\title{
Cuando los criollos escriben su historia
}

Espacio y tiempo en las Historias del Reino de Chile del abate Juan Ignacio Molina (1776-1795)

\section{Enrique Fernandez Domingo}

\section{Q OpenEdition \\ 1 Journals}

\section{Edición electrónica}

URL: http://journals.openedition.org/agedor/4917

DOI: 10.4000/agedor.4917

ISSN: 2104-3353

Editor

Laboratoire LISAA

Referencia electrónica

Enrique Fernandez Domingo, «Cuando los criollos escriben su historia », L'Âge d'or [En línea], 12 | 2019, Publicado el 01 octubre 2020, consultado el 14 octubre 2020. URL : http://journals.openedition.org/ agedor/4917 ; DOI : https://doi.org/10.4000/agedor.4917

Este documento fue generado automáticamente el 14 octubre 2020.

L'Âge d'or. Images dans le monde ibérique et ibéricoaméricain 


\title{
Cuando los criollos escriben su historia
}

\author{
Espacio y tiempo en las Historias del Reino de Chile del abate Juan \\ Ignacio Molina (1776-1795)
}

\section{Enrique Fernandez Domingo}

1 A finales del siglo XVIII, una parte de las respuestas a la representación de América y de los americanos que construye el discurso ilustrado europeo son propuestas por criollos que han estado o viven en Europa. Estos miembros de las élites ilustradas de la Monarquía hispánica, además de ser parte activa en la creación, reciben, conocen, comparten e interpretan los textos ilustrados que circulan en el espacio atlántico ${ }^{1}$. Juan Ignacio Molina (1740-1829), jesuita chileno exiliado en Italia a partir de 1768, publica, en 1776, su trabajo Compendio della storia geografica, naturale, e civili del regno del Chile. Es probable que durante su estancia en Bolonia, a partir de 1774, haya trabajado junto a Felipe Gómez de Vidaurre ${ }^{2}$ en la escritura de su compendio. La primera edición, publicada en dicha ciudad italiana, se acompaña de nueve láminas, un mapa de Chile y un plano de la ciudad de Santiago. El libro se divide en una primera parte que presenta un esbozo general del Reino de Chile, de su situación geográfica y aspectos naturales ríos, flora, fauna y minerales-, y una segunda donde se narran los acontecimientos ocurridos desde la conquista hasta 1655. La edición de la obra en español se hizo en dos volúmenes publicados en $1788^{3}$ y $1795^{4}$ respectivamente. Esta edición incorpora todas las modificaciones hechas por Molina en sus trabajos Ensayo de Historia Natural de Chile (1782) y Ensayo de Historia Civil de Chile (1787), ambos publicados en Italia.

2 Los textos de los jesuitas exiliados han sido analizados por diferentes investigadores ${ }^{5}$ que los han considerado tanto elementos formadores de una epistemología patriótica y catalizadores de la configuración de una identidad americana, como elaboraciones intelectuales que debaten, no sin paradojas, con la tradición historiográfica imperial llevando a cabo un cuestionamiento de las relaciones de asimetría entre americanos y europeos. Los escritos de Molina, más concretamente, han sido también abordados desde la tradicional historia de las ideas ${ }^{6}$, la historia cultural ${ }^{7}$, y han sido considerados, 
por ciertos autores, como prueba de la existencia de un "ser nacional chileno" anterior a la emancipación ${ }^{8}$.

\section{Contexto de escritura: la experiencia del exilio}

3 La Compañía de Jesús fue expulsada de los dominios imperiales por edicto del rey Carlos III en 1767, y posteriormente suprimida en 1773. Siguiendo las órdenes emanadas del dicho edicto, el gobernador Antonio de Guill y Gonzaga proscribe, el 25 de agosto de 1767, a los miembros de la orden religiosa establecidos en el Reino de Chile9. El resultado es la partida en exilio, a comienzos de 1768 , de entre doscientos ${ }^{10} \mathrm{y}$ trescientos cincuenta y dos jesuitas.

Todos nos miran como un árbol perfectamente seco e incapaz de revivir o como un cuerpo muerto y sepultado en el olvido... Entretanto nos vamos acabando. De 352 (jesuitas) que salimos de Chile, apenas queda la mitad, y de éstos los más están enfermos, o mancones que apenas pueden servir para caballos yerbateros. ${ }^{11}$

4 La mayor parte de los jesuitas exiliados del Reino de Chile se refugiaron, junto con otros miembros de la orden de los territorios americanos de la Monarquía hispánica, en el pueblo de Imola, en Italia, donde prosiguieron su labor cultural y religiosa: "Vivo persuadido de que tendrían una favorable acogida, siempre que saliesen á la luz, las tres historias compuestas últimamente por Don Pedro de Figueroa, y por los abates Don Miguel de Olivares y Don Felipe Vidaurre [...]"12.

5 Los jesuitas provenientes del Reino de Chile comparten discusiones, debates, conocimientos, noticias y recuerdos del país: "De estas (guerras), en estos últimos tiempos solo se cuentan dos, esto es, una en el año 1722, y la otra en 1767. Muchos de mis compatriótas, que viven aquí en Italia, se acuerdan todavia de los principales sucesos de ellas, mediante cuya ayuda puedo dar una suficiente relación"13. Estos intercambios se completan con la lectura de textos y libros que conciernen su patria ${ }^{14}$. En su descripción del reino de Chile, Molina es influenciado por los relatos de viajes que son el espejo de alguien que rememora, desde el viaje, la tierra visitada. Sin embargo, Molina escribe con la mirada hacia lo que deja atrás, desde la espera del exilio, y no como los viajeros que forman parte de sus lecturas que escriben lo que miran desde la idea del "no retorno". Además de los textos de viajeros y eruditos europeos sobre América, entre otras crónicas, Molina escribe a partir de la lectura de las obra de Alonso de Ovalle, de La Araucana de Alonso de Ercilla, un manuscrito de la Historia general del reino de Chile de Diego de Rosales y el de Miguel de Olivares sobre la Historia militar, civil y sagrada del Reino de Chile.

El primer tomo manuscrito de la Historia de Chile del Señor Abate Olivares, que tengo en mi poder, $\mathrm{y}$ otras relaciones impresas, me proveian los materiales necesarios para conducir mi obra hasta el año de 1655. El segundo tomo del dicho autor, que debia suministrarme el resto hasta nuestros tiempos, se hallaba en el Perú, pero me lisonjeaba poderlo tener dentro del mismo año. ${ }^{15 .}$

6 El desplazamiento del exilio activa a su vez redes socioculturales que designan circulaciones mentales y pueden establecer la geografía mental de un territorio susceptible de fundar una diferenciación en el espacio y en el tiempo: "Yo habia tambien pensado delinear un nuevo mapa general de Chile." ${ }^{16}$ Con respecto a su experiencia del exilio, Manuel Lacunza escribe: "Solamente saben lo que es Chile los que lo han perdido: no hay acá el menor compensativo; y esta es la pura y santa verdad: nadie puede saber lo que es Chile si no lo ha perdido" ${ }^{17}$. Las lecturas y la producción de 
los jesuitas se estructuran a partir de la "situación" desde donde se realizan ${ }^{18}$, es decir, un periodo (presente-pasado), un objeto (el territorio del Reino de Chile) y un lugar (Italia-Europa) desde donde piensan y experimentan su alteridad en el seno del saber ilustrado y la sociedad colonial. Paralelamente, esta práctica de escritura que se apoya sobre una praxis social ligada al exilo articula el acto intelectual propuesto y la sociedad que se quiere reflejar en sus obras.

\section{Contexto de escritura: filiaciones y transiciones discursivas}

7 Molina y Vidaurre se sitúan, al menos discursivamente, en el sistema político imperial:

El respeto que debo no me permite pasar adelante, principalmente con el justo temor de ofender la moderación de V. Exa., por lo que concluyo suplicándole a admitir la presente dedicatoria, como un acto, no tanto de obediencia a sus órdenes, que sino de particular adhesión a su persona, que Dios prospere para felicidad de la América y de la Corona, conservando su vida por muchos años. ${ }^{19}$.

8 Las dos obras de Molina que analizamos en este trabajo quedan configuradas, además de la experiencia del exilio, por el sistema desde el cual se elabora sus obras sobre el Reino de Chile. Este sistema es estructurado a partir de un proceso de acumulación de conocimientos y herramientas de pensamiento adquiridas desde unas instituciones académicas ligadas a la tradición letrada de la Ratio Studiorum ${ }^{20}$ y un modelo narrativocognoscitivo derivado de la relación entre la práctica misional y el conocimiento humanista ${ }^{21}$. Más allá de su carácter preceptivo, suponen un método de aproximación a los objetos de estudio, los fenómenos naturales y los grupos humanos que llega a coincidir con propuestas ilustradas que circulan en el espacio imperial ${ }^{22}$. Sus escritos, al mismo tiempo, son herederos de la ruptura de los esquemas historiográficos que supuso la llegada de los europeos al continente americano, es decir, el comienzo de un nuevo funcionamiento occidental de la escritura y la lectura ${ }^{23}$ así como la eliminación de la concepción del tiempo y espacio presente en la historiografía indígena ${ }^{24}$. Es desde este sistema de constitución de conocimientos que se estructuran, en las historias natural y civil del Reino de Chile de Molina, los binomios espacio-tiempo, naturalezahistoria y descripción-proceso. Este hecho provoca un momento de transición epistemológica - conceptualización, documentación, tratamiento, interpretación - que conduce a un comienzo de establecimiento de fuentes como principio de redistribución epistemológica de los momentos de la investigación propuesta por el jesuita chileno.

En el interior del contexto intelectual atlántico del último tercio del siglo XVIII, espacio en el cual se está estructurando una opinión pública ilustrada ${ }^{25}$, tiene lugar el desarrollo de proposiciones discursivas que abordan la cuestión del abandono del conocimiento supuesto inmediato en favor de un conocimiento mediado. Como vemos en la cita siguiente, Molina materializa en su análisis sobre las causas de los terremotos en el Reino de Chile la tensión que existe entre lo inteligible y lo inmediatamente visible.

Pretenden algunas personas, que observando el estado de la atmósfera, se puede anunciar con certeza la próxima venida de un terremoto. Yo no niego la posibilidad, mas confieso ingenuamente que habiendo ocupado toda mi atencion en combinar los varios aspectos que presenta aquella atmósfera siempre que tiembla la tierra, jamas pude deducir un indicio análogo que no fuese faláz en las circunstancias. En suma, puedo asegurar que como he nacido y me he criado en el Reyno de Chile, he 
visto temblar la tierra todas las estaciones del año, tanto en tiempo llovisoso, como en tiempo sereno; ya soplando con fuerza los vientos, y ya reynando la tranquilidad y la calma $\left[\ldots . . .{ }^{26}\right.$ limita a recibir información procedente de la experiencia sensible, sino que la conforma empleando elementos que posee a priori, son sus proposiciones sobre el clima chileno. Molina considera que las leyes naturales son idénticas que en Europa y, por lo tanto, que las diferencias climáticas entre los dos territorios corresponden a las mismas causas físicas. Además de realizar comparaciones entre los climas del Reino de Chile y los de los países vecinos, añade a su reflexión una concisa medición de la temperatura: "En los valles mediterráneos, donde siempre es mayor el calor, suele subir el mercurio en el termómetro de Réaumur á los 25 grados, y son deliciosísimas en el país las noches estivas. ${ }^{27}$ En este caso preciso, el paso de lo visible a lo inteligible se efectúa desde lo que se deja percibir a lo que se deja medir.

Sin embargo, la inquietud de un vínculo fuerte entre las proposiciones emanadas de la razón y la perspectiva cristiana sigue estando presente en la obra de Molina. A pesar de que la complejidad y especialización creciente de la ciencia, sobre todo a partir del último tercio del siglo XVIII, hagan que la figura de Dios comience a ser más discreta en favor de un corpus de saberes y métodos, cada vez más importante, imbuido de un carácter diferente del de las especulaciones teológicas y la literalidad de las interpretaciones bíblicas ${ }^{28}$, la influencia del pensamiento religioso está presente en la concepción ilustrada de la naturaleza que muestra Molina en sus reflexiones sobre las vetas de la cumbre del Paramillo. La historia natural profana se opone a la sagrada desarrollándose desde el dominio del cambio al de la duración, el tiempo frente la eternidad. Podemos observar en el texto la tensión palpable entre la escritura desde la cronología de la historia bíblica y la de la historia natural ilustrada.

Masas negras de arcilla petrificada, en las quales se ven encaxadas muchas piedras redondas, lisas [...] fenómeno que tal vez no será posible explicar como no recurramos á los efectos del diluvio universal, á no ser que haya quien pretenda que los Indios antiguos se divirtiesen en arrojar aquellas piedras en la arcilla [...] la inverosimilitud de tal conjetura; pues ademas de encontrarse una cantidad prodigiosa de las mismas piedras en lo interior de otras muchas, [...] como afirma el Abate Don Manuel de Morales, inteligente observador de la provincia de Cuyo su patria, que tuvo proporcion de exâminarlas con mucho cuidado, es absolutamente increíble que aquellos Indios quisiesen divertirse transportando á distancia de muchas leguas una inmensidad de piedras [...]. ${ }^{29}$

En el marco de la tradición escritural jesuítica, ligada íntimamente a las labores apostólicas, Molina exalta vivamente la naturaleza del Reino de Chile, y su escritura presenta, en una clara dialéctica con el continente europeo, una marcada apología del territorio de Chile, reino que representa aquí el conjunto de América, así como de sus habitantes y de la Creación divina.

[...] es el Reyno de Chile una de las mas considerables (regiones de América), no tanto por su extension, quanto por haver salido dotado de las manos de la naturaleza con parcialidad, y con particular cuidado; y por que, sostenida y favorecida de las delicias del clima, ha esparcido allí con prodigalidad sus mejores dones, exentos por la mayor parte de aquellas incomodidades que suelen acompañarlos en otros parages. Este país es, por decirlo así, la Italia, ó mas bien el jardín de la América meridional, en donde brilla con la misma perfeccion y abundancia que en la Europea todo quanto se puede apatecer para disfrutar una vida cómoda; pues hallandose situada la porcion mas considerable baxo los mismos 
grados de latitud, goza de los mismos climas; y extendiendose al modo de ésta mucho mas á lo largo que á lo ancho, tiene la proporción necesaria para recibir y madurar todo genero e producciones apetecibles. ${ }^{30}$ Para los naturalistas, el tiempo de la colecta comienza a ser superado y se debe proponer la clasificación de este inventario cuyos materiales son llamados a constituir las bases de una historia natural que intente comprender la complejidad de los fenómenos ${ }^{32}$. En este caso, la clasificación geográfica aparece como una respuesta posible. Paradójicamente, es la distancia que toma Molina durante su exilio con respecto al terreno la que le permite tomar en cuenta la medida del espacio geográfico. Este distanciamiento produce una reapropiación que se lleva a cabo a través del acto de ordenar y nombrar las especies animales y vegetales del Reino de Chile clasificándolos "según el sistema de Linneo" 33 y que "con mayor gusto" Molina "habria seguido á Waller ó á Bomare en la mineralogia, al gran Tournefort en la botánica, y á Brisson en la zoología, porque me parecen mas faciles y mas acomodados á la inteligencia común" 34 . La narración naturalista de Molina da paso a una reflexión en la que como sujeto, el jesuita chileno se implica en el objeto y, por extensión, en un conocimiento de una cultura particular.

\section{Contexto de escritura: la alteridad europea}

Giambattista Vico ${ }^{35}$ califica la historia, verdadero ámbito humano, como un conjunto de etapas que tiene unos patrones definidos. El objetivo fundamental de la escritura de la historia ya no se considera solo como el establecimiento de una serie de hechos, sino también, la constitución de estos como algo inteligible dentro de unos esquemas reconocidos que le dan sentido gracias al equilibrio entre los aspectos cognitivo, filosófico y literario. Entre ciertos miembros de las élites ilustradas del espacio atlántico se desarrolla, paralelamente, un cambio en la concepción del tiempo, desplazando paulatinamente su centro de gravedad hacia el futuro ${ }^{36}$, y en la consideración del concepto de revolución definido como ruptura y aceleración del proceso histórico: “[...] los Chilenos se mantuvieron poco tiempo en este estado de vida, hasta que una revolucion inesperada (la primera expedición de los españoles a Chile), los obligó en gran parte á recibir otras costumbres, y otros usos" ${ }^{37}$. Estas transformaciones, que favorecen estudios más eruditos, van relegando la concepción del tiempo de las crónicas donde el presente está siendo relatado como un puro presente y sin perspectiva de evolución.

16 A partir de estos principios, se materializa una pluralidad de escrituras en disputa sobre la historia de América. En este caso podemos referirnos, como ejemplo paradigmático, a la controversia letrada entre William Robertson y Francisco Javier Clavijero $^{38}$. También podemos señalar tres antecedentes claves que ponen de relieve la 
preocupación historiográfica por el pasado indígena: Idea de una nueva historia general de América septentrional (Madrid, 1746) de Lorenzo Boturini Benaducci, la Biblioteca mexicana (México, 1755) de Juan José Eguiara y Eguren y la Carta persuasiva al Señor Don Ignacio de Escandan sobre assunto de escribir la historia literaria de la América meridional (Cádiz, 1768) de José Eusebio de Llano de Zapata ${ }^{39}$.

17 Este enfoque nos conduce a otro tema central en la cuestión de la producción. En otras palabras, la inteligibilidad se instaura en relación con el otro a través del vínculo problemático que existe entre quien escribe y el objeto de la escritura. En nuestro caso, Molina apoya su reflexión sobre su propia experiencia, observación y conocimiento o las de sus colegas jesuitas. El jesuita chileno lleva a cabo una "toma de la palabra" directa para escribir una historia propia al espacio y el tiempo criollos. Este hecho le lleva, a partir de la observación sobre el terreno y una idea de objetividad dieciochesca, a discutir y cuestionar el conocimiento de los "filósofos de salón". Molina corrige los errores de estos últimos sobre la naturaleza chilena y sus habitantes, refutando así la idea de la inferioridad moral, estatismo temporal y deficiencia biológica de América con respecto a Europa.

Yo he visto, y he observado con suma atencion quantas cosas escribo; y no satisfecho con mi parecer, he consultado los escritores mas imparciales y mas apreciables que han reconocido las mismas cosas, y los quales, de acuerdo total con mis propias observaciones, son otros tantos apoyos irrefragables de quanto digo. Paw no solo no ha visto nada de lo que escribe y divulga, pero ni aun ha querido verlo en los autores que dice haber leído para formar su obra, pues sin embargo Frezier y Ulloa, á quienes cita con frequencia siempre que le acomoda, hablan de la maravillosa fecundidad con que el grano fructifica en el Reyno de Chile, él se atreve á decir á presencia de todo el mundo que el trigo nace únicamente en algunos ángulos del norte de América. ${ }^{40}$

En plena transición epistemológica, Molina asimila, por una parte, la escritura de la historia a la "descripción verídica de las cosas vistas", es decir, su conocimiento sobre el pasado del Reino de Chile proviene de admitir sin crítica alguna la autoridad del que ha visto los hechos, y critica, por otra parte, el pensamiento escolástico.

Si un caballo se cansa, sucede porque el Guecubu se ha montado en sus ancas: si la tierra se mueve, el Guecubu le ha dado un empujon [...] Este ente dañoso en suma, tiene sobre las desgracias la misma influencia que tenian las qualidades ocultas de los Escolásticos sobre los efectos físicos; y si su potencia fuese real, él seria el agente mas laborioso que exîstiese en este valle de lagrimas ${ }^{41}$.

Molina da preferencia a los relatos frente a los documentos, aunque estos sean accesibles. Estas "descripciones verídicas" separan pasado y presente por una simple yuxtaposición que se transforma en historia cuando Molina las dota, en su relato, de una cronología.

1558 [...] El famoso poeta Ercilla que era de la comitiva, queriendo tener la gloria de haberse introducido al mediodía mas que ningún otro Européo [...]1630 [...] Ajusticiamiento de un soldado español por los araucanos: "Muchos de los circunstantes, como afirma Don Francisco Bascuñan, testigo ocular, compadecieron la suerte del infeliz soldado". ${ }^{42}$

20 A nivel metodológico, sin embargo, Molina plantea el problema de las fuentes de una manera cada vez más general y compleja. Esto le lleva a introducir otros tipos de fuentes, lingüísticas y etnológicas, que desde numerosas poéticas europeas sobre América no se consideran legítimas: "Las investigaciones sobre las lenguas de las naciones salvages, ocupan al presente la atención de muchos filósofos. Por esto he 
creido conveniente dar al fin de esta obra una idea de la habla Chilena, la qual por su estructura y armonía, merece ser conocida." ${ }^{43}$ Molina propone un pasado expurgado de sus dimensiones míticas a través de la crítica de parte de sus fuentes - "De aquí tal vez tuvo origen la fábula de las Amazonas Chileñas, que algunos autores colocan en las comarcas australes de aquel Reyno" ${ }^{44}$-, entretanto que las de origen cristiano son válidas mientras se puedan intercalar en el relato y demuestren la influencia divina en el desarrollo histórico.

Quando estos vieron que la retirada era de veras, comenzaron á atribuir la fuga á favor especial del cielo, y en el fervor del entusiasmo no faltaron algunos que aseguraron que habian visto al Apostol Santiago sentado sobre un caballo blanco aterrar á los enemigos con una espada refulgente. La deposicion de ellos fue fácilmente creida. ${ }^{45}$

21 A su vez, su "Catálogo de los escritores de las cosas de Chile", que se encuentra al final de su historia civil, así como las múltiples notas de pie de página que reenvían a otros autores, muestran que Molina asume completamente la cultura escrita e impresa como un valor de conocimiento acumulativo y universal. Los textos citados en el "Catálogo", cuya narrativa suministró nuevos conocimientos sobre este territorio americano al imperio hispánico, se enfrentan ahora a una legitimación que comienza a plantearse a partir de la racionalidad crítica dieciochesca. A través del conocimiento directo del país y de la crítica de fuentes de la literatura ilustrada sobre el continente americano, Molina experimenta su propia alteridad con Cornelio De Pauw (Rechercbes philosophiques sur les Américains, 1768-1769), el abate Francois Raynal, Histoire philosophique et politique des établisssements et du comerce des Européens dans les deux Indes (1770) o William Robertson, History of America (1777).

El desafío lanzado por Molina, en este caso, concierne menos al paralelo entre Antiguos y Salvajes que al modelo de historia progresiva elaborado por los historiadores ilustrados:

Las naciones ${ }^{46}$ por una cierta especie de inércia, propia de la condicion humana, permanencen por mucho tiempo estacionarias, aun quando las circustancias pareciesen favorables á sus adelantamientos. El pasage de la barbarie á la vida civil, no es tan facil como á primera vista podria creerse. La historia de las naciones cultas nos demuestra la verdad de esta proposicion [...] Confesemos que todas las naciones sean americanas, europeas o asiáticas, han sido semejantísimas en estado salvaje, del cual ninguna ha tenido el privilegio de eximirse. ${ }^{47}$

Molina se aboca al estudio de un solo territorio, el Reino de Chile, que en su alteridad con las obras de los ilustrados europeos viene a representar toda América, y a partir de él construye un esquema de historia válido para toda la humanidad ${ }^{48}$. El jesuita chileno parte del principio agustiniano de la unidad del género humano, en el cual la predestinación y la salvación son los motores de la historia. Sin embargo, en sus historias este principio es confrontado a la concepción dieciochesca de una aptitud universal, una trayectoria común, pero no simultánea, a la "civilización". Para Molina los indígenas no parten de la nada, tienen un origen, ya que poseen un lenguaje, que define el tiempo lineal e histórico del Reino de Chile, y tras la llegada de los "Peruanos", una poética del pasado: "Las primeras noticias que tenemos de ellos, las han suministrado los anales del Perú, cuyos habitantes, como mas civiles, fueron mas solícitos en conservar la memoria de los sucesos notables." ${ }^{49}$

Capítulo primero, "Origen, fisionomia, y lengua de los Chilenos". Siempre que se reflexione la armoniosa estructura y riqueza de la lengua propia de este pais, parece que la nacion Chilena haya sido en otro tiempo mas culta de los que es al presente, ó 
á lo menos que ella sea un residuo de algun gran pueblo ilustrado, el cual debió caer por alguna de aquellas revoluciones físicas, ó morales, á las quales está tambien sujeto nuestro globo. La perfeccion de las lenguas sigue constantemente la de la civilizacion; ni se puede comprender cómo una nacion siempre salvage, que jamas ha sido limada ni por las sabias leyes, ni por el comercio, ni por las artes, pueda hablar un idioma culto, expresivo, y abundante [...] como si jamas hubiesen habido, ó no hubiesen al presente otros salvages en el antiguo continente, cuyos usos, é idiomas son igualmente reprehensibles. Apenas se hallará una costumbre entre los Americanos, que no se encuentre la misma, ó la ánaloga en las demás partes de la tierra. $^{50}$

De este modo quiere afirmar que los pueblos indígenas del Reino de Chile no son sociedades degeneradas, sino sociedades que tienen un ritmo evolutivo más lento. Molina, por ejemplo, considera, apoyándose en Leibniz, que los Araucanos forman parte de la humanidad y, que como parte de ésta, desde su origen conocen una evolución similar a la del resto de las "naciones": "Si acaso es verdad, como escribe el célebre Leibniz, que los hombres jamas han demostrado mayor talento que en los diferentes juegos que han inventado, los Araucanos pueden lisonjearse de no ser inferiores en esta prerogativa á las demas naciones" ${ }^{51}$. Los "Salvajes" se convierten para Molina, que otorga al lenguaje la función de depósito de todos los conocimientos, en testigos que hay que interrogar, en huellas que hay que interpretar para esclarecer el pasado más lejano.

De esta breve noticia filológica podría el Señor Paw inferir, no ser verdadera su asercion, con la qual quiere dar á entender, que todas las lenguas americanas son por sí mismas asperas y pobres de voces. Esta y otras semejantes proposiciones suyas absolutas, quando aun fuesen hasta cierto punto verídicas, serian siempre susceptibles de mil excepciones. Habria decidido mas bien reflexionar, que para hablar decisivamente de las varias lenguas de un vasto continente era menester á lo menos haber consultado antes algunas de sus gramáticas, y jamas fiarse de las relaciones de los viajeros, las quales deben estar llenas de imperfectísimas nociones, porque una lengua no se aprende de paso. ${ }^{52}$.

El recurso a los Antiguos permite la inserción de los indígenas en una red de referencias conocidas tanto por los criollos como por los europeos $\mathrm{y}$, al mismo tiempo, permite, de una cierta forma, "domesticar a los Salvajes" ${ }^{53}$. Así, con respecto a la forma de gobierno de los Araucanos, Molina parte de la división aristotélica de las formas de gobierno para escribir que "es anterior a la época del arribo de los Españoles, y sirve de base al gobierno civil de los Araucanos, el qual es aristocratico, como lo ha sido el de quasi todas las naciones barbaras"54. Para Molina la etimología del "Chileno o Araucano" es historia de las cosas significadas por estas palabras tal como se puede trazar en su "noticia filológica" desarrollada en los capítulos "Idea de la lengua Chilena" e "Indice de algunos verbos Chilenos" de su historia civil. En estos capítulos, Molina se apoya en términos comparables a aquellos usados por los pensadores europeos que se volcaban hacia la antigua herencia griega y romana para dar su visión de Europa.

De donde se ve, que en la habla Chilena el artículo se pospone al nombre, al contrario de lo que se practica en las lenguas modernas de Europa. Esta especie de declinacion no era de todo incógnita á los Latinos, y á los Griegos, entre los quales se encuentran algunos nombres declinados casi del mismo modo, bien que con mas variedad. ${ }^{55}$

Pero incluso siendo una lengua hablada por "Salvajes", que no se puede situar al mismo nivel de evolución que las lenguas europeas consideradas como "cultas" y "civilizadas", 
el "habla Chilena" tiene una estructura gramatical similar a ellas, y sobre todo contiene en ella una concepción del tiempo.

Se puede tambien observar, que esta lengua, aunque usada por gente bárbara, é inculta, tiene en su conjugacion todos los tiempos necesarios, lo que no se puede decir igualmente de muchas otras lenguas, sin exceptuar algunas de aquellas que se estiman cultas. Se sabe quanto la habla Inglesa sea defectuosa en sus conjugaciones. La lengua Alemana, que es la madre de ella, carece del preterito simple, del futuro del indicativo, y de todos los tiempos simples del subjuntivo. Yo no pretendo po resto anteponer el lenguaje Chileno á las susodichas lenguas, ni menos igualarlo. Sé bien que este no está falto de defectos considerables; pero con todo no se puede negar, que el fondo sea bueno, y susceptible de perfeccion. ${ }^{56}$

El pasado anterior a la llegada de los conquistadores es considerado como algo que tiene su propio tiempo y que los propios antepasados poseen las herramientas necesarias para considerarlo como parte de un proceso, como parte de la historia.

Ademas él (Paw) levanta el grito, porque en estos idomas no sabe encontrar algun vocablo capaz de significar el tiempo, la duracion, el espacio, la materia, la forma, ni algun otro ser metafísico, ó moral. Por no hablar de los otros lenguajes americanos, si el Señor Paw hubiese entendido el Chileno, habria encontrado en él todas estas voces, [...]. ${ }^{57}$

Molina quiere mostrar la evidencia de una historia previa a la conquista, es decir, la apertura de la posibilidad para el Reino de Chile de tener una historia en la cual poner en solfa el discurso sobre la inmovilidad de los "Salvajes" americanos frente al dinamismo de los "civilizados" europeos.

\section{Lugar de escritura: la alteridad indígena}

Como escribe Michel de Certeau, toda historiografía establece un temps des choses como contrapunto y condición de un "tiempo discursivo"58. Según De Certeau, la historiografía cambia constantemente en relación con la historia que se estudia, el lugar desde donde se elabora y la forma de encajar el pasado, el presente y el futuro. El discurso histórico de Molina, mediatizado por la técnica de producción, refleja una identidad espaciotemporal en el acto de diferenciarse de una época anterior o de otra sociedad. Sus historias tienden a querer probar que desde el lugar donde se produce se es capaz de pensar el pasado. Este lugar de producción es marcado en el texto a través de la palabra criollo, atributo de carácter subrayado por la tipografía itálica, acto de distinción del lugar y tiempo desde el cual se escribe.

Entre los mismos criollos que Paw quisiera reducir si pudiese á una vida corta, he conocido yo viejos de 104, 107, y 115 años; mi abuelo paterno y mi visabuelo, que tambien fueron criollos, vivieron prosperamente, el uno 95 años, y el otro 96, siendo todavía mucho mas comunes estos esxemplos entre los indigenas ó nativos de aquellas tierras..$^{59}$

Molina posiciona su escritura al mismo nivel potencial de evolución y cualidades que los europeos más "civilizados", y si no es el caso es a causa de la falta de medios y de una situación no provocada por las características "naturales".

Su poblacion (del Reino de Chile) en general es compuesta de Européos, de Criollos, de Indios, de Negros, y de Mestizos. Los Européos, fuera de algunos pocos Franceses, Ingleses, y Italianos, son todos Españoles [...] Los Criollos, que forman allí el mayor número, son los descendientes de los Européos. El carácter de ellos, fuera de algunas pequeñas diferencias provenientes del respectivo clima o del gobierno, es enteramente semejante al de todos los demas Criollos americanos oriundos de 
cualquier nacion Européa. Las mimas ideas y las mismas qualidades morales se descubren en todos. Esta uniformaidad, muy digna de reflexion, no se que haya sido considerada por algun filósofo en toda su extension. Por todo lo qual, lo que los viageros inteligentes y sin preocupacion han escrito en quanto á la índole de los Criollos Franceses é Ingleses, se puede sin equivocacion aplicar á estos de Chile. Son estos generalmente dotados de buen ingenio, y tienen buen éxito en todas las facultades, á las quales se aplican. Hacian progresos notables en las ciencias útiles, como los han hecho en la metafísica que se les enseñaba, si tuviesen aquellos estímulos, y aquellos medios que se encuentran en Europa. No se reconoce en ellos algun particular apego á las preocupaciones, y si alguna vez las tienen, se despojan de ellas facilmente, luego que advierten lo bueno, y lo útil. ${ }^{60}$

31 En cuanto a la historiografía, la escritura de Molina se desarrolla desde un lugar de transición. Por un lado, se apoya en las enseñanzas de Heródoto ${ }^{61}$ presentando los actores, sus acciones y su desenlace con la idea de detener el tiempo para que no llegue a desvanecerse la memoria de los hechos públicos realizados por los hombres.

Don Garcia era, ó por índole, ó por sistema, inclinado al rigor. El fue el primero que introduxo en aquella guerra, contra el parecer de la mayor parte de sus Oficiales, el uso inhumano de mutilar, ó de hacer morir á los prisioneros; esta deliberacion podrá ser quizá buena para contener un pueblo vil, ó acostumbrado á la servidumbre. ${ }^{62}$

Por otro lado, emplaza las acciones de los hombres en una historia ideal dispuesta por la providencia, en torno de la cual se lleva a cabo el relato de las historias particulares que debe conservar en la memoria las "grandes" y "maravillosas" hazañas llevadas a cabo.

El indómito Araucano es incapaz de ceder á los mas fuertes reveses de la fortuna. Las pérdidas mismas, tan lejos de abatirlo ó desmayarlo, antes parecen infundirle mas vigor, y mas valor [...] Uno solo que quede, dice el experto historiador Tesillo, no dudará de oponerse á los progresos de nuestras armas. Esta constancia, ó llamese contumancia si se quiere, es ciertamente maravillosa, por no decir heroica. ${ }^{63}$

Al mismo tiempo, la escritura de Molina se estructura desde un orden del tiempo que diferencia el presente y el pasado y plantea un cierto distanciamiento del objeto de estudio. El jesuita chileno instituye en su obra una ruptura entre el pasado y el presente, es decir, la experiencia del pasado se realiza desde el presente, lugar desde donde se produce su historiografía. Molina piensa históricamente el Reino de Chile a partir de las herramientas de reflexión contemporáneas, elabora sus historias desde un orden del tiempo determinado ${ }^{64}$ mostrando las temporalidades que las estructuran y las ordenan sin asimilar la dinámica que anima la vida histórica a las leyes de la naturaleza, que dependen de Dios: "Los Chilenos empiezan á hacer figura en la historia despues de la mitad del siglo XV de nuestra era. Los hechos anteriores á ésta época permanecen sepultados en la obscuridad de los tiempos por falta de monumentos" 65 . Apelando a los Incas, el jesuita chileno periodiza el pasado prehispánico del Reino de Chile: "El Inca Yupanqui, que segun mi cómputo, reynaba en el Perú hácia el año de 1450, informado de estas ventajosas qualidades de Chile resolvió tentar su conquista." ${ }^{66}$ Molina realiza el esfuerzo de remontar el tiempo estableciendo fechas, duraciones y periodos y construyendo el pasado indígena a partir de un juego de espejos con la sociedad colonial.

La historización del mundo indígena, presentada bajo una forma estandarizada y atractiva, es un acto que lo engarza con la historia colonial. En un tiempo lineal, el presente indígena es intercalado en la cronología evolutiva del Reino de Chile. El primer capítulo del Libro primero del Compendio de la historia civil del Reyno de Chile 
aborda el origen de los Chilenos para continuar, a partir del presente de los indígenas que viven en el Reino de Chile, el tiempo lineal de su relato y engarzar la conquista "peruana" con la llegada de los europeos. La fundación de la ciudad de Concepción sirve de punto cronológico que abre el Libro segundo en el que Molina, desde el presente, propone un estudio etnológico de los indígenas. Al intercalarlo en el relato de los hechos sucedidos durante la conquista y la colonia, que continúa en el Libro tercero, Molina le otorga a su estudio un lugar preciso en su cronológica evolutiva del reino de Chile. En esta cronología, el jesuita chileno proyecta sobre el pasado indígena categorías y marcos cronológicos coloniales y se apropia de este pasado desde un interés subjetivo criollo y la defensa de América frente a la literatura ilustrada europea.

Los hombres en los progresos que hacen para adelantarse hácia la perfeccion de la vida civil, pasan succesivamente por quatro grandes estados ó periodos. De cazadores se hacen pastores, despues agricultores, y finalmente comerciantes, época que forma el hombre verdaderamente civil. Los Chilenos quando fueros conocidos la primera vez de los Españoles, se encontraban en el tercer periodo; ellos no eran ya cazadores, sino agricultores. ${ }^{67}$

El presente colonial es presentado como el momento de un proceso histórico que no se diferencia del propuesto desde Occidente para el continente europeo. En la escritura de Molina es el Occidente quien dicta el pasado, aunque es, paradójicamente, el mismo Occidente el que da la posibilidad del análisis de su criollidad histórica. Para el jesuita chileno su presente es la etapa avanzada del proceso histórico materializada en el orden político, comercial, espiritual y material de la sociedad colonial.

1787. La Corte, informada de la muerte de Gonzagfa, mandó á gobernar aquel país á Don Augustin Jauregui, el qual obtuvo después, con aplauso universal, el relevante empleo de Virey del Perú. Don Ambrosio Benavides que le ha sido subrogado, hace al presente felices aquellas poblaciones, con su prudente y benéfica administración. ${ }^{68}$.

Posicionado desde la sociedad colonial, Molina se nutre de la memoria antropológica para escribir la historia anterior a la llegada de los "Peruanos". Sin origen no hay pasado, y Molina interpela un pasado que no ha terminado a partir del estudio etnológico-interpretado como un verdadero documento histórico- de los indígenas contemporáneos: "Los Auracanos, que son los custodios fieles de todos los conocimientos y usos antiguos de los Chilenos"69. La atención que Molina lleva a todos los aspectos de la vida indígena, incluso a los aspectos religiosos y ceremoniales, otorga a la sociedad indígena una profundidad ausente en las crónicas de los siglos precedentes. Sin embargo, Molina muestra en su escritura toda la dificultad que tiene de oscultar la sociedad indígena en el tiempo y sus evoluciones y no únicamente como una estructura inmóvil. Construyendo el pasado indígena desde el presente, Molina proyecta sobre los Araucanos marcos de estudio precisos salidos directamente de las categorías coloniales: división administrativa, forma de gobierno, constitución política, leyes civiles, infantería, caballería, general, milicia, ...

El cuerpo de sus leyes, que se conserva por tradicion, se denomina Admapu, que quiere decir, las costumbres del pais. Efectivamente estas leyes no son otra cosa que sus primeros usos, ó las tácitas convenciones que se han establecido entre ellos, como fueron en sus principios quasi todas las leyes de las demas naciones, y por conseqüencia tienen los vicios propios de tales constituciones, pues no siendo escritas, no pueden ser, ni bastante públicas, ni bien compendiosas..$^{70}$

El lugar de su escritura como criollo enfrenta a Molina a la alteridad temporal y cultural indígena. La descripción detallada del modo de vida de los indígenas en su historia civil -estructura política, religión, "carácter", agricultura, comercio, caza, industria, comida, licores, metales, herramientas, vivienda, números- marca con 
insistencia la ruptura temporal que manifiesta una sociedad colonial para la cual el tiempo pasado no puede ser más que un tiempo clausurado, tanto por razones políticas como religiosas. Molina se sirve del presente para escribir el pasado indígena, pero también para indicar el momento en que los indígenas se encuentran en el proceso de civilización con respecto a la "criollidad", haciendo, al mismo tiempo, un esbozo de clasificación según el estado de proceso de civilización en el que se encuentran.

Aunque los Araucanos hayan salido mucho tiempo hace del estado salvage, con todo conservan todavia en muchas cosas las preocupaciones y el carácter propio de aquel primitivo periodo de la vida humana [...] Los Chiquillanes, que algunos tienen falsamente por un aduar de los Pehuenches, habitan al N.E. de estos, sobre las faldas orientales de los Andes. Estos son los mas bárbaros, y por conseqûencia los menos numerosos de todos los Chilenos [...]. ${ }^{71}$

La idea de ruptura temporal acompaña la idea de una evolución hacia la "civilización" que dirige a los indígenas hacia la verdad absoluta de la religión católica. Ello hace posible la abolición de la distancia religiosa, a priori infranqueable, que separa el politeísmo del monoteísmo.

El sistema de religion de los Araucanos es simple, y acomodado á su manera libre de pensar y de vivir. Ellos reconocen un Ente supremo, autor de todas las cosas, á el qual dan el nombre de Pillan: esta voz deriva de púlli ó pilli (la alma) y denota el espíritu por execelencia. Lo llaman tambien Guenu-pillan, el espíritu del Cielo, Butagen, el gran Ser; Thalcave, el Tomate; Vilvemvoe, el Creador de todo; Vilpepilvoe, el Omnipotente; Mollgeli, el Eterno; Avnoli, el infinito. ${ }^{72}$

A partir de este razonamiento, Molina no evita describir el estado de evolución en que se encuentran los indígenas con respecto a sus prácticas y creencias espirituales.

De donde se ve, que el sistema de dos proncipios opuestos, impropiamente llamado maniqueismo, es muy esxtendido, ó por mejor decir, se encuentra establecido en casi todas las naciones bárbaras de ambos continentes [...] Si los Auraucanos se muestran podo cuidadosos de sus divinidades, son por otra parte muy supersticiosos en otros puntos de menor importancia [...] Consultan en todos sus negocios de conseqüencia á los adivinos, ó sean los charlatanes de lo por venir, que se llaman ya Lligua, ya Dugol (los hablantes) [...] Aunque no conozcan la diferencia que hay entre el cuerpo y el alma, todavia sus ideas sobre la espritualidad de esta, no parecen muy limpias, como se deduce de las ceremonias que practícan en sus funerales. ${ }^{73}$

\section{Conclusiones} un sistema de formación y de pensamiento hispánico, como en el seno de un dinámico contexto intelectual de circulación de discursos, prácticas y personas en un espacio atlántico del cual el jesuita chileno es activo participante e interesado "intermediario cultural"74. El resultado de su proposición discursiva es una forma de producción de conocimiento que evoca un momento de transición epistemológico a partir de la puesta en relación de discursos diferentes sobre América, una experiencia vital, como es el exilio, y el bagaje cultural de su formación intelectual. Sus historias natural y civil del reino de Chile, en definitiva, implican una epistemología más cercana al discurso de los hechos que a los hechos en sí.

La relación entre el campo de experiencia y el horizonte de expectativa que se expresa en las historias de Molina no está aún lo suficientemente separada para mostrar en sus escritos una dinámica de negación política del sistema colonial y una proposición 
orientada hacia el futuro. Molina, en las obras estudiadas, en ningún momento intenta hacer corresponder la cultura y la lengua en un marco de soberanía política orientado hacia el futuro. El jesuita chileno no busca mostrar una unidad orgánica de la nación, en este caso en el sentido moderno del concepto, para alcanzar la totalidad nacional. Sin embargo, el jesuita chileno comienza a liberarse poco a poco del peso de la tradición y empieza a sentirse capaz de rebasar los límites espaciotemporales gracias a la constitución de una historia erudita que se atribuye un saber fundado en el conocimiento del pasado a través de los documentos y de la mirada etnológica, considerados ambos como fuentes básicas para su escritura de la historia.

Si bien Molina se posiciona en gran parte de su historia civil como un cronista del pasado que se interesa por las prácticas humanas de los indígenas, más allá de la restitución de la gesta político-militar tradicional, el jesuita chileno opera un ensamblaje entre la historia de anticuario y la historia filosófica, combinando la preocupación de las fuentes y el recurso al método filológico. Molina intenta dar una inteligibilidad a su relación factual, sus historias pasan de sincronismos, indispensables para establecer el antes y el después, a la sincronización, estableciendo, según una escala de tiempo determinada, un "antes que" y un "después que" 75 de la evolución y del atraso del Reino de Chile. Su criollidad, finalmente, no se convierte, en sus historias, en una unidad de acción políticamente eficaz. El lugar desde donde escribe Molina no le permite concretizar un concepto que vaya más allá de una designación o denominación temporalizada y territorializada. Su criollidad, en el contexto preciso de la producción de sus historias, no es una unidad de definición política o social, no es una autodesignación que haga surgir una noción sociopolítica contraria al sistema colonial.

\section{NOTAS}

1. Según Bailyn, el espacio atlántico constituye una unidad de análisis propia, un vasto espacio unitario e integrado en el seno del cual son estudiadas las relaciones entre Europa, Asia y las Américas a partir de una perspectiva transnacional y comparativa. El espacio atlántico es, a su vez, un espacio interracional en continuo movimiento que debe ser estudiado a través de las dinámicas de cambio y desarrollo. Cf. Bernard Bailyn, Atlantic History. Concept and Contours, Cambridge, Harvard University Press, 2005.

2. Félix Gómez de Vidaurre, Historia geográfica, natural y civil del Reino de Chile, manuscrito de 1789, publicado como libro en Santiago en 1889 (con introducción biográfica y notas por J. T. Medina).

3. Abate Don Juan Ignacio Molina, Compendio de la historia geográfica, natural y civil del Reyno de Chile escrito en italiano por el Abate Don Juan Ignacio Molina, Madrid, Antonio de Sancha, 1788.

4. Abate Don Juan Ignacio Molina, Compendio de la historia civil del Reyno de Chile traducida y aumentada por varias notas de Nicolás de la Cruz y Bahamonde, Madrid, Imprenta de Sancha, 1795.

5. Antonello Gerbi, La disputa del Nuevo Mundo. Historia de una polémica 1750-1990, México, FCE, 1982; David, Brading, Orbe indiano. De la monarquía católica a la república criolla 1492-1867, México, FCE, 1991; Luis, Millones Figueroa y Domingo, Ledezma (dir.), El saber de los jesuitas, historias naturales y el nuevo mundo, Francfort-Madrid, Iberoamericana-Vervuert, 2005; Jorge, Cañizares, Cómo escribir la historia del Nuevo Mundo: historiografías, epistemologías e identidades en el mundo del Atlántico del 
siglo XVIII, México, FCE, 2007; Marc André, Bernier, Clorinda, Donato y Hans-Jürgen, Lüsebrink, (dir.), Jesuit Accounts of the Colonial America: intercultural transfers, Intellectual Disputes, and Textualities, Toronto, University of Toronto Press, 2014.

6. Januario Espinosa, El abate Molina: uno de los precursores de Darwin, Santiago, Zig-Zag, 1946.

7. Francisco Orrego González, "Juan Ignacio Molina y la comprensión de la naturaleza del Finis Terrae. Un acercamiento desde la Historia (cultural) de la Ciencia”, ARBOR Ciencia, Pensamiento y Cultura, vol. 187-751, Madrid, septiembre-octubre 2011, p. 961-976.

8. Hernán Briones Toledo, El abate Juan Ignacio Molina: ensayo crítico-introductorio a su vida y obra. Santiago, Andrés Bello, 1968; Walter, Haniscc, Juan Ignacio Molina y sus obras, Talca, Editorial Universidad de Talca, 1999.

9. La denominación de Reino, en este caso, no significa ningún estatuto jurídico especial, y administrativamente el trato es de Gobernación o Capitanía General. El uso del nombre lo toma la Corona, incorporándolo a las leyes de Indias desde principios del siglo XVII. El término reino se emplea frecuentemente en las cédulas reales.

10. Walter Hanisch, Itinerario y pensamiento de los jesuitas expulsos de Chile: 1767-1815, Santiago, Andrés Bello, 1972, p. 229.

11. Manuel Lazcuna citado en Francisco Antonio, Encina, Historia de Chile, tomo 10, Santiago, Ercilla, 1983, p. 80.

12. Abate Don Juan Ignacio, Molina, op. cit., 1978, p. VII (en todas las citas sacadas de los textos del Abate Molina se ha conservado la ortografía original).

13. Abate Don Juan Ignacio Molina, op. cit., 1975, p. VI.

14. Las acepciones de "patria" vigentes en la América setecentista son: como ciudad, país, lugar en el que se ha nacido, como concepto de patria general americana, como el lugar propio de cualquier cosa aunque sea inmaterial. Ver: Fernández Sebastián Javier, Diccionario político y social del mundo iberoamericano. Patria, Universidad del País Vasco, Centro de Estudios Políticos y Constitucionales, Madrid, 2014.

15. Abate Don Juan Ignacio Molina, op. cit.,1975, p. V.

16. Ibid, p. VII.

17. Citado en Francisco Encina, op. cit.,1983, p. 80.

18. Michel De Certeau, L'Invention du quotidien, tome I, Arts de faire, Paris, Gallimard, 1990.

19. Felipe Gómez de Vidaurre citado en Marcos A., Figueroa Zúñiga, "Historia geográfica, natural y civil del Reino de Chile (1782) del jesuita expulso Felipe Gómez de Vidaurre: una obra injustamente desvalorizada por la historiografía chilena", in Anuario de Estudios Americanos, n 74, vol. I, Sevilla, enero-junio, 2017, p. 155-183.

20. Alejandra Contreras Gutiérrez, "La enseñanza jesuita en Chile colonial: sus colegios, universidades y una aproximación a sus métodos y contenidos", in Revista Historia de la Educación latinoamericana, $\mathrm{n}^{\circ} 22$, vol. 22, Colombia, enero-junio 2014, p. 35-50.

21. Francisco Orrego, "Juan Ignacio Molina y la comprensión de la naturaleza del Finis Terrae. Un acercamiento desde la historia (cultural) de la ciencia", ARBOR Ciencia, Pensamiento y Cultura, $\mathrm{n}^{\circ}$ 751, vol. 187, Madrid, 2011, p. 961-976.

22. Alejandra Contreras Gutiérrez, "La Ratio Studiorum de la Compañía de Jesús: un aporte al desarrollo pedagógico y cultural del Chile colonial", in Revista de Estudios y Experiencias en Educación, n 32, vol. 16, Santiago, diciembre 2017, p. 137-148.

23. El "Nuevo mundo" es territorializado gracias a una descripción detallada que "trae ante los ojos aquello que se muestra": gente, hechos, tiempos, lugares, la descripción es clara y visible y favorece la visión a partir de la lectura y la escucha. Cf. Jesús María, Carrillo Castillo, Naturaleza e imperio. La representación del mundo natural en la Historia general y natural de las Indias de Gonzalo Fernández de Oviedo, Madrid, Editorial Doce Calles, 2004.

24. Serge Gruzinski, La Machine à remonter le temps. Quand l'Europe s'est mise à écrire l'histoire du monde, Paris, Fayard histoire, 2017. 
25. Para François Furet constituye un nuevo modo de relaciones entre los ciudadanos y el poder. Jürgen Habermas piensa que la nueva sociabilidad crea un especio crítico en el cual se utiliza públicamente la razón. Keith Michael Baker retoma también la expresión tribunal de la opinión definiendo la opinión pública -basada en la razón y con la reflexión de los hombres ilustrados tanto como fuente- como fruto de la comunicación universal entre los hombres y del progreso de las Luces que como instrumento de unidad y consenso que eliminaba las divisiones y parcialidades. Cf. François, Furet, Penser la Révolution française, Paris, PUF, 1978; Jürgen Habermas, L'espace public. Archéologie de la publicité comme dimension constitutive de la société bourgeoise, Paris, Payot, 1988; Keith Michael Baker, Au tribunal de l'opinion-Essai sur l'imaginaire politique au XVIII siècle, Paris, Payot, 1993.

26. Abate Don Juan Ignacio Molina, op. cit.,1978, p. 35-36.

27. Ibid., p. 26.

28. Olivier Perru, Hommes d'Église et science au XVIII ${ }^{e}$ siècle : vers une harmonie entre raison, nature et création, Paris, Vrin, et Lyon, Institut interdisciplinaire d'études épistémologiques, 2012, p. 629.

29. Abate Don Juan Ignacio, Molina op. cit., 1978, p. 104.

30. Ibid., p. II-VI.

31. Ibid., p. 167-168.

32. Marie-Noëlle Bourguet et Christian Licoppe, "Voyages, mesures et instruments : une nouvelle expérience du monde au Siècle des Lumières ", Annales Histoire, Sciences Sociales, $\mathrm{n}^{\circ} 5$, Paris, 1997, p. 1115-1151; Claude, Blanckaert, « Histoires du terrain entre savoirs et savoir-faire ", in Claude, Blanckaert (dir.), Le terrain des sciences humaines. Instructions et enquêtes (XVIII ${ }^{e}$ XIX ${ }^{e}$ siècle), Paris, L'Harmattan, 1996, p. 9-55.

33. Abate Don Juan Ignacio Molina, op. cit., 1978, p. 388.

34. Ibid., p. XII.

35. Giambattista Vico, Principios de una Ciencia nueva sobre la naturaleza común de las naciones, tomo I, Buenos Aires, Aguilar, 1960 [1725], p. 43.

36. Reinhart Koselleck, Le futur passé. Contribution à la sémantique des temps historiques, Paris, Editions de l'EHESS, 1990.

37. Abate Don Juan Ignacio Molina, op. cit., 1975, p. 28 (ortografía del texto originale).

38. Silvia Sebastiani, "Las escrituras de la historia del Nuevo Mundo: Clavijero y Robertson en el contexto de la Ilustración europea”, Historia y grafía, n³ 37, México, 2011, p. 203-236.

39. Boturini, apoyándose en los principios de la Ciencia nueva de Giambatista Vico (1725-1730), intenta demostrar que los pueblos indígenas no sólo tienen cultura sino también historia. Aunque Eguiara y Eguren considera la cultura indígena como un pasado clausurado, siguiendo la práctica historiográfica del momento, el novohispano hace un alegato del saber autóctono frente a la conciencia europea.

40. Abate Don Juan Ignacio Molina, op. cit., 1978, p. XV (ortografía del texto originale).

41. Abate Don Juan Ignacio Molina, op. cit., 1975, p. 85.

42. Ibid., p. 189 et p. 278.

43. Ibid., p. VIII.

44. Ibid., p. 177.

45. Ibid., p. 131.

46. "Nación: el acto de nacer/La colección de los habitadores de alguna provincia, país o reyno. Se usa frequentemente en singular para significar cualquier extranjero", Diccionario de la lengua castellana, Madrid, por D. Joaquín Ibarra, impresor de Cámara de S.M. y de la Real Academia, 1783. "Los habitantes de Chile se dividen en indigenas ó nativos, en generacion Europea, y en raza Africana. [...] pero los nativos Chileños forman una sola nacion dividida en varias tribus [...]". Cf. Abate Don Juan Ignacio Molina, op. cit., 1978, p. 378 (ortografía del texto originale).

47. Abate Don Juan Ignacio Molina, op. cit., 1975, p. 25 et p. 359 (ortografía del texto originale). 
48. Beatriz González Stephan, "Sujeto criollo/conciencia histórica: la historiografía literaria en el período colonial”, in José Anadón (dir.), Ruptura de la conciencia hispanoamericana, Madrid, FCE, 1993, p. 15-58.

49. Ibid, p. 8-9.

50. Abate Don Juan Ignacio, Molina, op. cit., 1975, p. 5 et p. 357-358.

51. Ibid., p. 124.

52. Ibid., p. 357.

53. Stephen, Greenblatt, Marvelous possessions. The wonder of the new World, Oxford, Oxford University Press, 1991.

54. Abate Don Juan Ignacio, Molina, op. cit.,1975, p. 60.

55. Ibid., p. 337.

56. Ibid., p. 347-348.

57. Ibid., p. 357.

58. Michel De Certeau, op. cit., 1990.

59. Abate Don Juan Ignacio, Molina, op. cit., 1978, p. 378.

60. Abate Don Juan Ignacio, Molina, op. cit., 1975, p. 315-317.

61. Ibid., p 324.

62. Ibid., p. 176.

63. Ibid., p. 202.

64. Este orden del tiempo es «Traduit pour une culture, une des formes de son rapport au temps, une manière de redistribuer le passé, proche ou lointain, de lui faire une place sans lui abandonner toute la place ", cf. François, Hartog, Anciens, modernes, sauvages, Paris, Galaade, 2005, p. 28

65. Abate Don Juan Ignacio, Molina, op. cit., 1975, p. 9. En el siglo XVIII comienza la arqueología de campo y el estudio de las antigüedades como fuentes históricas, $c f$. Paula Ermila, Rivasplata Varillas, "La arqueología precientífica en el Perú en el siglo XVIII", Letras Históricas, n 13, México, otoño 2015-invierno, 2016, p. 221-252.

66. Ibid., p. 10.

67. Ibid., p. 12.

68. Ibid., p. 302.

69. Ibid., p. 27.

70. Ibid., p. 62.

71. Ibid., p. 110 et p. 226.

72. Ibid., p. 84.

73. Ibid., p. 85-90.

74. Peter Burke, La Renaissance européenne, Paris, Le Seuil,2000.

75. François Hartog, Croire en l'histoire, Pairs, Flammarion, 2016, p. 156.

\section{RESÚMENES}

A partir del análisis de las historias civil y natural del Reino de Chile del abate Juan Ignacio Molina, este trabajo quiere indagar el contexto espitemológico y el lugar desde son producidas estas dos obras. Este estudio propone, al mismo tiempo, analizar las relaciones discursivas entre tiempo, espacio e identidad presentes en las dos historias del jesuita chileno. 
À partir de l'analyse des histoires civile et naturelle du Royaume du Chili de l'abbé Juan Ignacio Molina, cet article veut étudier le contexte épistemologique et le lieu de production de ces deux ouvrages. Cet article propose, également, d'analyser les rapports discursifs entre le temps, l'espace et l'identité présents dans les deux histoires du jésuite chilien.

ÍNDICE

Mots-clés: Molina (Abate), criollo, espace atlantique, indiens, Lumières

Palabras claves: Molina (Abate), criollo, espacio atlántico, indígenas, Ilustración

\section{AUTOR}

ENRIQUE FERNANDEZ DOMINGO

Université Paris 8, LER-ALHIM 